\title{
The Swedish Fracture Register - ten years of experience and 600,000 fractures collected in a National Quality Register
}

Michael Möller ${ }^{1,2^{*}} \mathbb{0}$, Olof Wolf ${ }^{3}$, Carl Bergdahl1 ${ }^{1,2}$, Sebastian Mukka ${ }^{4}$, Emilia Möller Rydberg ${ }^{1,2}$, Nils P. Hailer ${ }^{3}$, Jan Ekelund ${ }^{5}$ and David Wennergren ${ }^{1,2}$

\begin{abstract}
Background: Before the creation of the Swedish Fracture Register (SFR), there was no national quality register that prospectively collects data regarding all types of fractures regardless of treatment in an emergency setting. Observational data on fractures registered in a sustainable way may provide invaluable tools for quality improvements in health care and research.
\end{abstract}

Description: Tenyears after its implementation, the Swedish Fracture Register has 100\% coverage among orthopaedic and trauma departments in Sweden. The completeness of registrations reached in $202069-96 \%$ for hip fractures at the different departments, with the majority reporting a completeness above $85 \%$. The Swedish Fracture Register is a fully web-based national quality register created and run by orthopaedic professionals, with financial support from public healthcare providers and the government. All users have full access to both the registration platform and all aggregated statistics in real time. The web-based platform was created for use in health quality registers and it has easily gained acceptance among users. The register has gradually developed by the addition of more fracture types and skeletal parts.

Research activity is high and 31 scientific publications have been published since 2016. The strategy from the start was to publish validation data and basic epidemiological data. However, over the past few years, publications on outcomes, such as re-operations and mortality, have been published and four register-based, randomised, controlled trials are ongoing.

Conclusion: It is possible to create a fracture register, to gain professional acceptance and to collect fracture data in a sustainable way on a national level if the platform is easy to use. Such a platform can also be used as a randomisation platform for prospective studies.

Keywords: National quality register, Fracture, Classification, Fracture outcome

\section{Background}

Injuries to the skeletal system are a major cause of disability in all age groups and the treatment of fractures and their sequelae constitutes a major part of total societal

\footnotetext{
*Correspondence: michael.moller@vgregion.se

2 Department of Orthopaedics, Sahlgrenska University Hospital, Gothenburg/Mölndal, Sweden
}

Full list of author information is available at the end of the article spending on health care [1]. Thousands of studies have addressed cohorts of fracture patients, but, to the best of our knowledge, the Swedish Fracture Register (SFR) was the first population-based register designed for prospective data collection on patients with all types of fractures, regardless of treatment [2]. Ten years after its initiation in 2011, no other quality register of this kind has been original author(s) and the source, provide a link to the Creative Commons licence, and indicate if changes were made. The images or other third party material in this article are included in the article's Creative Commons licence, unless indicated otherwise in a credit line to the material. If material is not included in the article's Creative Commons licence and your intended use is not permitted by statutory regulation or exceeds the permitted use, you will need to obtain permission directly from the copyright holder. To view a copy of this licence, visit http://creativecommons.org/licenses/by/4.0/. The Creative Commons Public Domain Dedication waiver (http://creativeco mmons.org/publicdomain/zero/1.0/) applies to the data made available in this article, unless otherwise stated in a credit line to the data. 
Table 1 Development of features in the Swedish Fracture Register

\begin{tabular}{ll}
\hline When? & What? \\
\hline 2010 & Creation of the database platform \\
2011 & Registrations; humeral and tibial fractures \\
2011 & Patient-reported outcomes on paper forms \\
2012 & Registrations; all fracture types in adults except in the spine \\
2015 & Registrations; fractures in children \\
2015 & Registrations; fractures in the spine \\
2015 & Registrations; periprosthetic fractures \\
2016 & Registrations visible at departments not performing the initial registration \\
2019 & Automatic information exchange fracture vs arthroplasty register \\
2019 & EQ5D-3 L replaced by EQ5D-5L \\
2019 & Patient-reported outcomes on electronic forms \\
2020 & Knowledge support system for ankle fractures \\
\hline
\end{tabular}

constructed, implemented and used for quality improvement and research on fracture treatment in all body parts.

The SFR has evolved from being a single-centre register with data collection on only two fracture types in 2011 to include all fracture types and reach $100 \%$ national coverage in 2021: All 54 trauma and orthopaedics departments in Sweden participate in data entry in the SFR. The SFR became the first platform for register-based, randomised, controlled trials (r-RCTs) in fracture care $[3,4]$. The complexity of registrations and the need for registrations to be made within the setting of accident and emergency departments are obstacles to overcome. Legal issues in many countries limit the way registers can be constructed and used. The personal identity number (PIN) given to every Swedish citizen at birth or after permanent immigration plays a key role in the way quality registers can be maintained and cross-linked. Internationally, there are many local or regional databases that are mainly run by hospitals or groups of hospitals [5, 6]. The early development of the SFR has been described previously $[2,7]$, and the aim of the present study is to describe and discuss the further development of the SFR as a tool for research and quality improvement.

\section{Construction and content}

In the SFR, information on fractures of all types is collected, except for those to the ribs and skull, which are not treated by orthopaedic surgeons in Sweden. All data entry is performed by the orthopaedic resident or surgeon. Fractures in all locations of the adult skeleton (with closed physes) are registered. Fracture registration in children (with open physes) is limited to long bone fractures, mainly because the inclusion criterion is a positive radiographic finding. In small children in particular, many injuries to fingers, toes and clavicles are diagnosed and treated without radiographic confirmation.

Following a brief section on the trauma mechanism, the fracture/ $-\mathrm{s}$ are classified and subsequently used as the starting point for treatment registrations. A time line of treatments with planned treatments or re-operations always follows the specific registered fracture, even in a polytrauma situation.

In Table 1 a time-line for developments in the Fracture Register is shown (Table 1 ).

The main feature of a well-functioning quality register is easy data input and readily available data for extraction and analysis. In the SFR, three outcome measurements are available; re-operations, patient-reported outcome measurements (PROM) and mortality.

First, the reoperation rate is dependent on accurate registrations of performed re-operations. This process, with its strengths and limitations, has been validated in defined cohorts $[8,9]$.

The second outcome is PROM, consisting of the generic EQ5D-5L and the Short Musculoskeletal Function Assessment (SMFA). PROM registration went digital in 2019 when all patients were invited to answer the EQ5D-5 L and the SMFA questionnaires electronically. A few weeks after the injury a code is sent by standard mail to all patients, asking them to answer the web-based questionnaires using a recall technique on their functional status the week before the fracture occurred. Those who respond are invited to fill out the one-year followup questionnaires as well. The response rate is monitored continuously on the website at unit level and ranges from approximately $65 \%$ as its best at injury time and $15 \%$ as the lowest at 1 year, depending on age group, fracture type and department. Studies evaluating PROM results 
and response rates in the SFR are ongoing, but only a few have so far been published $[10,11]$.

Mortality rates are available as the third outcome measurement [12]. Death dates from the Swedish Tax Agency are updated on a daily basis to the SFR, enabling calculations of mortality rates.

\section{Database improvements}

A quality register needs to be distinguished from a research database. A quality register has to be sustainable, using only a minimum of variables, and a userfriendly interface for registration. Otherwise, if too many variables are included, as they are in a research database, there is a risk that no registrations whatsoever will be made in busy working hours.

The SFR is fully web based and more than 3000 users can access the website to register fractures. At the same website, information is available in the form of aggregated data from the SFR and also regarding detailed data for every single fracture registered at the user's own department. A great deal of effort has been put into involving the user through the availability of data and also recently by using data as knowledge support.

Communication from a register to its users is essential when running a quality register based on non-mandatory registrations. Published recurring newsletters, half-yearly reports specific to each department and a frequently updated website are part of the strategy. The annual report is published with data and analyses and scientific summaries of different fracture locations [13-21]. On the website, real-time data on performance appear and the number of patients included in ongoing $r$-RCTs is shown. All users have full access to statistics on an aggregated level. This enables the very important notion among users that "we own the data that we have entered and we can easily access and use them".

\section{Specific feature for secondary fracture prevention}

One register feature that has real potential to improve clinical practice is the search engine developed in the SFR to find fractures related to osteoporosis. As a database feature, it is very simple, but it has the potential to resolve an otherwise almost insoluble task. Many patients have fragility fractures, some of which also suffer from osteoporosis [22-26]. Fragility fractures are a growing concern due to their increasing incidence and they are associated with huge costs to society [1]. Secondary prevention with advice, i.e. fracture liaison services, change of lifestyle factors and medication with antiresorptive drugs, significantly reduce the rate of new fractures after the first fragility fracture [27]. However identify patients with recently sustained fragility fractures have previously been difficult. Using the database feature developed for the
SFR, the task of finding these patients can now be performed easily and automatically. If the fracture has been registered in the SFR, the register provides users with a feature allowing for a standardised search for suspected osteoporosis-related fractures. All fractures to the upper arm, wrist, spine, pelvis or femur in patients 50 year of age or above can be retrieved with PINs. These patients can subsequently be offered further investigations of bone mineral density and antiresorptive treatment, if necessary. This feature is used by many departments active in the SFR and the time saving adds up to one of the easy pay-backs after implementing the SFR. In fact this search option will be the foundation of the ongoing development of regional and national guidelines for secondary fracture prevention in Sweden.

\section{User interface and value}

The interface in the SFR is user friendly, and the use of pictograms for classification is the essential starting point. The alternatives for treatment registrations which are then available are only those relevant to the chosen fracture. This makes registrations more accurate and less time consuming. Even though data entry is considered fast and easy, it is probably beneficial to adherence to registration if more features which will benefit the surgeon making the registration are added. The SFR can be regarded as an education tool that teaches the young surgeon how to classify fractures. The use of statistics can teach the relationship between the severity of the fracture, choice of treatment and outcome. If feedback is given at the time of fracture classification and/or at the time of treatment registration, this can benefit both the young surgeon and the quality of registration, as well as the standard of care.

\section{Real-time feedback}

In 2020, a system for real-time feedback regarding ankle fractures was implemented in the SFR. After a pilot project had been evaluated, the system was introduced nationwide. It aims at ensuring that the chosen classification takes account of both radiographic findings and clinical examination results. The evident background is the importance of ankle joint congruity and the observed difficulty involved in correctly classifying ankle fractures [11]. An error in fracture classification could be the starting point of incorrect treatment. The feedback function has obtained a high degree of acceptance, but its influence on decision-making is still to be evaluated.

\section{Coverage}

The implementation process has been described for the early years [7] and in 2020, all 54 orthopaedic departments treating fractures in Sweden had committed to 
Table 2 Time line for achievements in the Swedish Fracture Register

\begin{tabular}{ll}
\hline When? & What? \\
\hline 2011 & 1/54 departments participating \\
2012 & 6/54 departments participating \\
2013 & 16/54 departments participating \\
2014 & $27 / 54$ departments participating \\
2015 & $36 / 54$ departments participating \\
2015 & First scientific publication \\
2015 & 100,000 fractures registered \\
2017 & $45 / 54$ departments participating \\
2019 & $47 / 54$ departments participating \\
2019 & First orthopaedic r-RCT \\
2019 & First thesis based on SFR data \\
2020 & Annual registration over 100,000 fractures \\
2020 & 500,000 fractures registered \\
2020 & $54 / 54$ departments participating = 100\% coverage \\
2021 & 30th scientific publication \\
2021 & 600,000 fractures registered \\
\hline
\end{tabular}

register fractures in the SFR on a daily basis (Table 2). Other national fracture registers have been planned, but to date none has been implemented in daily practice. In recent years, some more elaborate plans have been published [28].

\section{Completeness}

Completeness of registrations in a national quality register is essential, if a high degree of external validity is to be obtained. The continuous assessment of completeness is needed and this requires a reference with which the data in the SFR can be compared. The reference data must be easy to retrieve and must contain the "true" number of fractures treated in the country. The only source of data that may fulfil these criteria in Sweden is the National Patient Register (NPR). However, the matching of fractures in the SFR with the NPR is not without its challenges. Since the NPR overestimates the true number of fractures an algorithm for case selection in the NPR has been developed [29]. This enables annual completeness analyses of fracture registrations in the SFR using the NPR for comparison. Since 2017, annual analyses of completeness based on this algorithm have been published on the SFR website, at the Swedish Board of Health and Welfare and in the annual reports from the SFR. Fractures to the humerus, wrist, hip, femur, tibia and ankle in adults and humeral and femoral fractures in children are evaluated. Most departments achieve completeness according to the current algorithm in the area of $70-90 \%$ for the evaluated fracture types [13-21]. In 2020 hip and femur fracture registrations ranged from 69 to $96 \%$ (mean approximately 85\%) and wrist fracture registrations from 31 to $96 \%$ (mean approximately 70\%) among the 47 departments registering fractures during the entire 2020.

\section{Research activity}

Since the SFR is a new national quality register and the first of its kind, there was a need to evaluate the validity of data collected in the SFR. The first studies to be conducted were therefore validity studies regarding the accuracy of fracture classification in the SFR, completeness in fracture registration and evaluation of responders versus non-responders regarding PROM [11, 29-35]. The next reasonable step was to conduct descriptive studies of the epidemiology, incidence and mortality of different fractures [22-26, 36-40]. Studies designed to evaluate outcome after the treatment of fractures have been conducted and many are ongoing $[8,9,41,42]$. Most publications have focused on the validation of essential features in the SFR or have been descriptive, basic epidemiological studies, as was the intention described above. For details on the development, see Table 2.

One of the main developments of the SFR database functionality in recent years is the creation of a research study platform for r-RCTs. Two large r-RCTs have been started and are ongoing since 2019 and 2020 respectively. The protocols for the Hipsther and the Duality studies have been published [3, 4]. Both studies focus on hip fractures and follow small studies in the same field. The aim is to use the national quality register platform to enable many departments to co-operate and include 1400-1600 patients per study over a study period of approximately 4 years. To the best of our knowledge, the Hipsther study was the first $\mathrm{r}$-RCT in orthopaedics. A study on the treatment of spine fractures, Sun Burst, started in 2021 and two more studies will start in 2022. The FFT (fracture Fragility Trial) will investigate secondary fracture prevention. The recruitment of patients will use the SFR database to search for recently sustained fragility fractures. Following consent to participate, patients will be randomised to either a bone-modifying drug or a placebo in a double-blinded way. In this way, the non-mandatory registration made by professionals has resolved a highly complex logistical problem that involves the same category of patients and also serves as the foundation of a r-RCT. A decline in fracture incidence following widespread and successful anti-osteoporotic treatment is likely to occur. A change in incidence of this kind will be possible to monitor in the SFR, since time trends in fracture occurrence are continuously analysed. The Daicy-study is a cluster randomised trial that will investigate the rate of deep infection after hemiarthroplasty for displaced cervical hip fractures in over 7000 


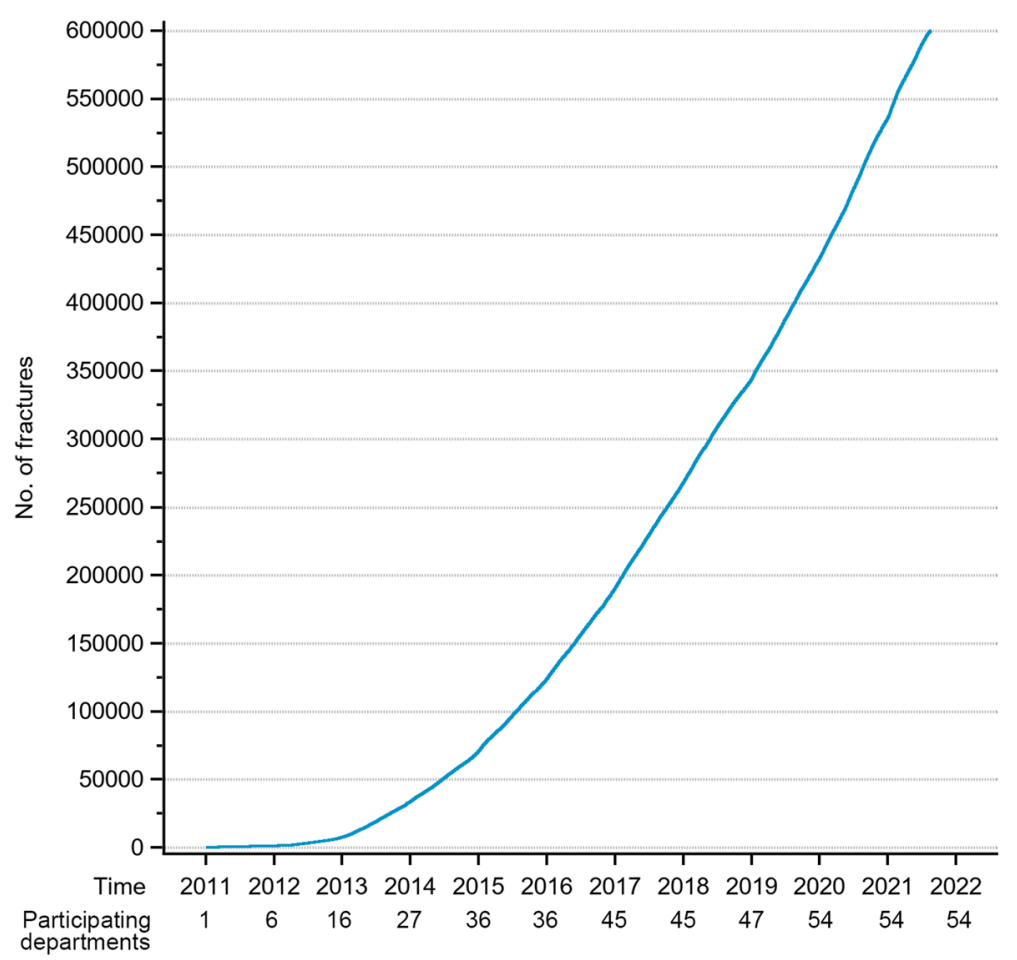

Fig. 1 Cumulative number of registered fractures and participating departments 2011-2021

patients randomised between single and dubble antibiotic impregnated bone cement.

In these r-RCTs, the database is used not only as a tool to find the patients for an ongoing study but also as the screening instrument. In the first step, the registering surgeon at sites active within the study will be advised that the patient appears to fulfil the inclusion criteria for the specific study. In the second step, the screening process can take place on the research study platform and, after a four-question screening including informed consent, the patients, if eligible, can be randomised to different treatment methods. In this way, it is safe and easy to include patients with an acute fracture and also to manage randomisation without delaying the time to surgery. The data from screening and onwards are kept as a separate study database, while treatment is registered in the SFR as usual. All follow-up including outcomes in terms of mortality, re-operation and dislocation respectively, will take place by linking with other registers. Half the orthopaedic departments (from small local hospitals to university hospitals) in Sweden participate in these studies, thereby enabling a rapid inclusion of patients.

\section{Descriptive data}

As an illustration of how users and healthcare providers are able retrieve aggregated data, the following section contains some examples of the statistics available from the database. In 2020, 103,400 fractures were registered, and in August 2021, the total number of registered fractures reached 600,000 (Fig. 1). The 10 most frequent fracture locations are shown in Fig. 2 for three defined age groups ( $a, b$ and $c)$. In overall terms, the most common fracture types for both genders taken together, in adults and children, are shown in Figs. 3 and 4. In Fig. 5, the distribution of age at fracture is shown for all registered fractures, demonstrating that the most common age group sustaining a fracture is the group of individuals aged between 71 and 80 years.

\section{Future perspectives}

The future perspectives include the use of more appropriate and diversified PROMs. The implementation in 2019 of web-based questionnaires created an opportunity to use different PROMs for different fracture locations and also using fewer questions. In this area, the SFR is confined to following the ongoing development of available means of collecting PROMs developed by the Swedish Association of Local Authorities and Regions (SALAR).

The implementation of the Medical Device Regulation in all European countries from May 2021 imposes significant obligations on both implant manufacturers and caregivers relating to the documentation of implant use, traceability and post-market surveillance. The SFR has the potential to provide detailed data on treatment 

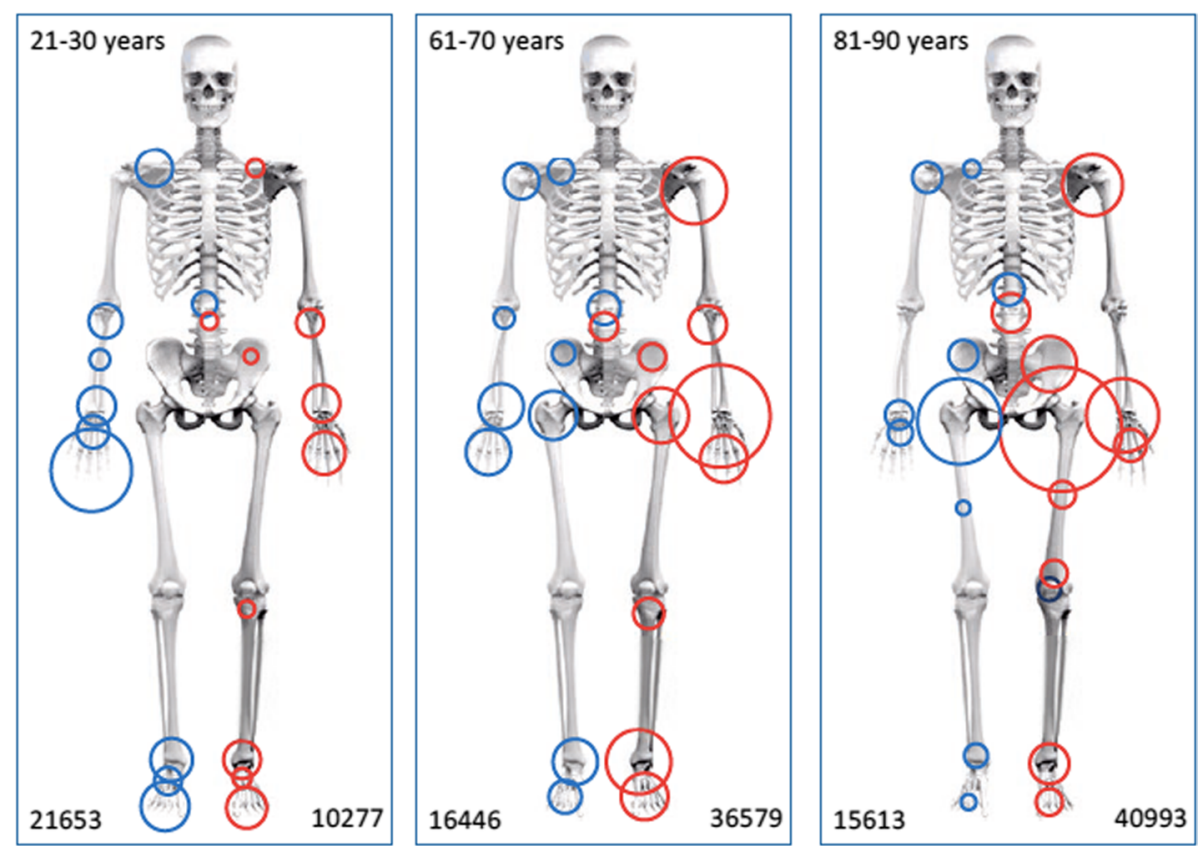

Fig. 2 a-c The ten most frequent fracture locations are shown with circle sizes proportional to the number of registered fractures in age groups a 20-30years, b 60-70years and c 80-90years in blue for men and red for women. Number of fractures are shown at the bottom of the figures

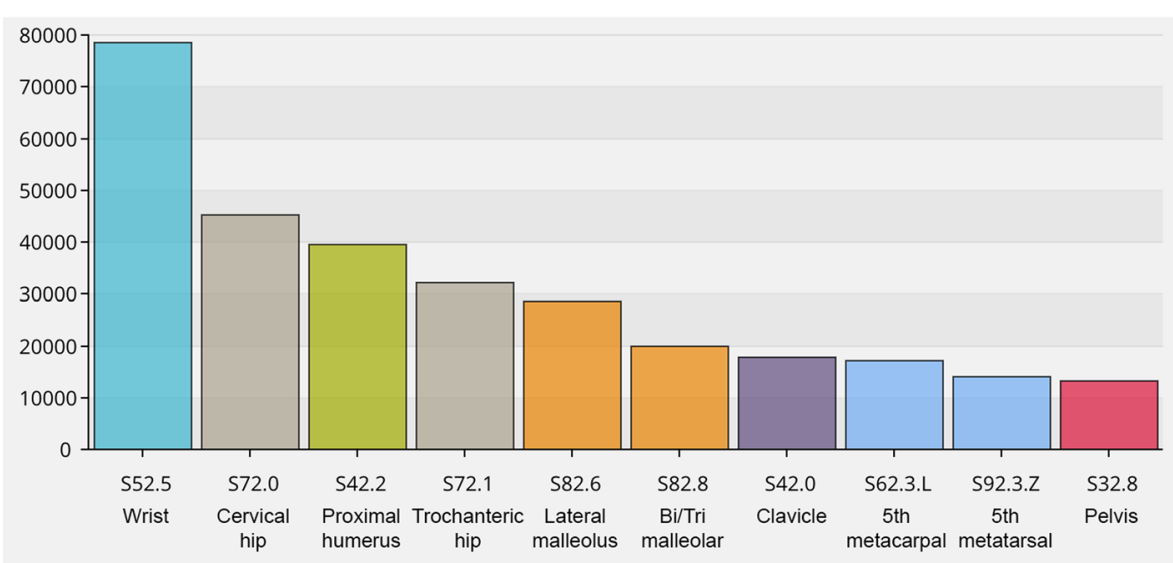

Fig. 3 The ten most common fracture types in adults (fractures with closed physes) $2012-2021(n=306,000)$

success related to different implants. A recently started project aims to implement the inclusion of implant data using bar-code readers and the GTIN specification made available by the implant producers to the SFR. If this feature is implemented successfully, data on implant performance can be used to meet the legal traceability requirements in Europe. The introduction of new implants can be surveilled in detail with prospectively collected data. This can ensure the step-wise introduction of new implants with the potential for the early detection of less favourable implant designs on the market.

A 100\% coverage among fracture-treating orthopaedic and trauma departments was achieved early in 2021. The next step in the development is the inclusion of the six university hospital hand surgery departments. In Sweden, only a small number of fractures are treated at private units. In the future, data from these units could contribute data, in particular 


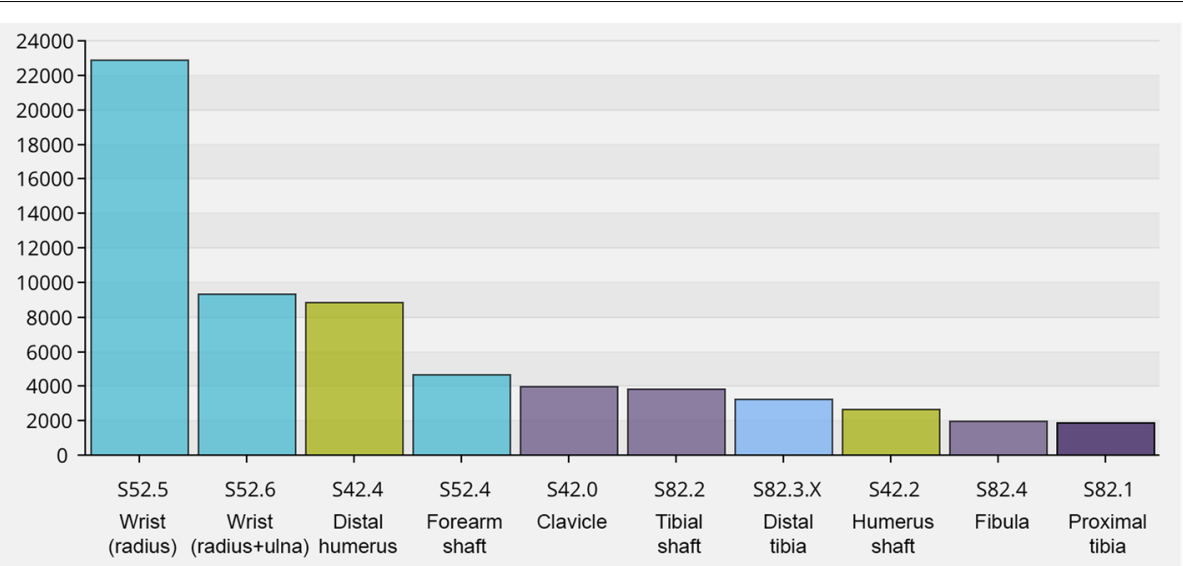

Fig. 4 The ten most common fracture types in children (fractures with open physes) 2015-2021 ( $n=63,227)$

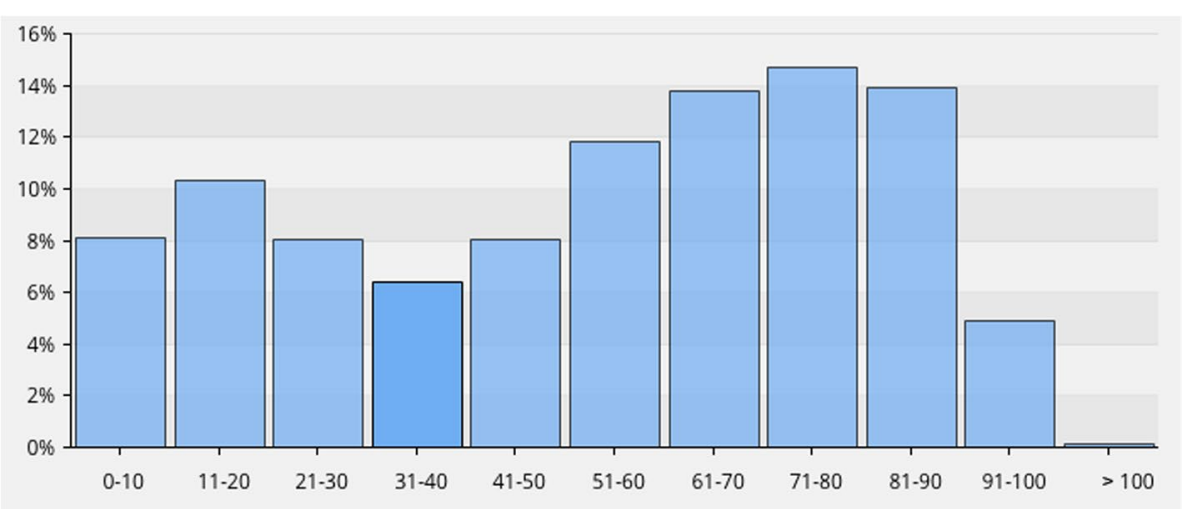

Fig. 5 Distribution in age groups of registered individuals with fractures 2011-2021 $(n=604,245)$

data on minor re-operations, such as the removal of metalware.

\section{Conclusions}

The creation of a user-friendly National Quality Register, like the unique Swedish Fracture Register, has enabled registrations of fractures on national scale. Real time registrations have made pragmatic $\mathrm{rRCTs}$ possible for patients with hip fractures. A high degree of coverage and completeness has been obtained due to gradual improvements and close co-operation with the orthopaedic profession. Future developments should focus on the addition of features that can increase the utility of data and the value to users making their registrations during busy working hours.

\section{Abbreviations}

SFR: Swedish Fracture Register; NPR: National Patient Register; SMF: Short Musculoskeletal Function Assessment; SALAR: Swedish Association of Municipalities and Regions; STA: Swedish Tax Agency.

\section{Acknowledgements}

The authors wish to thank all the orthopaedic surgeons at the affiliated departments for entering detailed data on busy working days. The authors also wish to thank Carl Ekholm for the creation of Fig. 2a-c and Jeanette Kliger for the language revision of the manuscript. The author(s) read and approved the final manuscript.

\section{Authors' contributions}

MM, OW and DW conceived the study concept. MM and JE performed the data collection and analysis. MM wrote the initial draft. MM, OW, DW, NH, SM, $\mathrm{CB}, \mathrm{JE}$ and ER revised and rewrote the final manuscript and contributed to the interpretation of data. The author(s) read and approved the final manuscript.

\section{Funding}

Open access funding provided by University of Gothenburg. 


\section{Availability of data and materials}

The datasets generated and/or analysed during the current study are available at the SFR (www.frakturregistret.se) with a log-in which can be obtained from the corresponding author in response to a reasonable request.

\section{Declarations}

\section{Ethics approval and consent to participate}

The study with Dnr 2020-04662 was approved on 21 October 2020 by the Swedish Ethical Review Authority. No consent is needed from patients registered in a Swedish national quality register. Using an opt-out system, patients may withdraw their participation at any time.

\section{Consent for publication}

Not applicable.

\section{Competing interests}

The authors declare that they have no competing interests.

\begin{abstract}
Author details
${ }^{1}$ Institute of Clinical Sciences, Sahlgrenska Academy, University of Gothenburg, Gothenburg, Sweden. ${ }^{2}$ Department of Orthopaedics, Sahlgrenska University Hospital, Gothenburg/Mölndal, Sweden. ${ }^{3}$ Department of Surgical Sciences, Orthopaedics, Uppsala University, Uppsala, Sweden. ${ }^{4}$ Department of Surgical and Perioperative Science (Orthopaedics), Umeå University, Umeå, Sweden.

${ }^{5}$ Centre of Registers Västra Götaland, Gothenburg, Sweden.
\end{abstract}

Received: 7 September 2021 Accepted: 24 January 2022 Published online: 11 February 2022

\section{References}

1. Svedbom A, Hernlund E, Ivergård M, Compston J, Cooper C, Stenmark J, et al. Osteoporosis in the European Union: a compendium of countryspecific reports. Arch Osteoporos. 2013;8(1):137.

2. Wennergren D, Ekholm C, Sandelin A, Moller M. The Swedish fracture register: 103,000 fractures registered. BMC Musculoskelet Disord. 2015;16:338.

3. Wolf O, Sjoholm P, Hailer NP, Moller M, Mukka S. Study protocol: HipSTHeR - a register-based randomised controlled trial - hip screws or (total) hip replacement for undisplaced femoral neck fractures in older patients. BMC Geriatr. 2020;20(1):19.

4. Wolf O, Mukka S, Notini M, Moller M, Hailer NP, Duality G. Study protocol: the DUALITY trial-a register-based, randomized controlled trial to investigate dual mobility cups in hip fracture patients. Acta Orthop. 2020;91(5):506-13.

5. Ahn H, Court-Brown CM, McQueen MM, Schemitsch EH. The use of hospital registries in orthopaedic surgery. J Bone Joint Surg Am. 2009;91(Suppl 3):68-72.

6. Meling T, Harboe K, Arthursson AJ, Søreide K. Steppingstones to the implementation of an inhospital fracture and dislocation registry using the AO/OTA classification: compliance, completeness and commitment. Scand J Trauma Resusc Emerg Med. 2010;18:54.

7. Wennergren D, Moller M. Implementation of the Swedish fracture register. Unfallchirurg. 2018;121(12):949-55.

8. Wennergren D, Bergdahl C, Selse A, Ekelund J, Sundfeldt M, Moller M. Treatment and re-operation rates in one thousand and three hundred tibial fractures from the Swedish fracture register. Eur J Orthop Surg Traumatol. 2021;31(1):143-54.

9. Bergdahl C, Wennergren D, Swensson-Backelin E, Ekelund J, Moller M. No change in reoperation rates despite shifting treatment trends: a population-based study of 4,070 proximal humeral fractures. Acta Orthop. 2021. https://doi.org/10.1080/17453674.2021.1941629.

10. Lagergren J, M MO, Rogmark C. Displaced femoral neck fractures in patients 60-69 years old - treatment and patient reported outcomes in a register cohort. Injury. 2020;51(11):2652-7.

11. Juto H, Gartner Nilsson M, Moller M, Wennergren D, Morberg P. Evaluating non-responders of a survey in the Swedish fracture register: no indication of different functional result. BMC Musculoskelet Disord. 2017;18(1):278.
12. Bergh C, Moller M, Ekelund J, Brisby H. 30-day and 1-year mortality after skeletal fractures: a register study of 295,713 fractures at different locations. Acta Orthop. 2021;92(6):739-45. https://doi.org/10.1080/17453674. 2021.1959003.

13. Swedish Fracture Register. Annual Report 2011-2012. 2013.

14. Swedish Fracture Register. Annual Report 2013. 2014

15. Swedish Fracture Register. Annual Report 2014. 2015.

16. Swedish Fracture Register. Annual Report 2015. 2016.

17. Swedish Fracture Register. Annual report 2016. 2017.

18. Swedish Fracture Register. Annual Report 2017. 2018.

19. Swedish Fracture Register. Annual Report 2018. 2019.

20. Swedish Fracture Register. Annual Report 2019. 2020.

21. Swedish Fracture Register. Annual Report 2020. 2021

22. Bergdahl C, Ekholm C, Wennergren D, Nilsson F, Moller M. Epidemiology and patho-anatomical pattern of 2,011 humeral fractures: data from the Swedish fracture register. BMC Musculoskelet Disord. 2016;17:159.

23. Wennergren D, Bergdahl C, Ekelund J, Juto H, Sundfeldt M, Moller M. Epidemiology and incidence of tibia fractures in the Swedish fracture register. Injury. 2018;49(11):2068-74.

24. Mattisson L, Bojan A, Enocson A. Epidemiology, treatment and mortality of trochanteric and subtrochanteric hip fractures: data from the Swedish fracture register. BMC Musculoskelet Disord. 2018;19(1):369.

25. Rundgren J, Bojan A, Mellstrand Navarro C, Enocson A. Epidemiology, classification, treatment and mortality of distal radius fractures in adults: an observational study of 23,394 fractures from the national Swedish fracture register. BMC Musculoskelet Disord. 2020;21(1):88.

26. Bergh C, Wennergren D, Moller M, Brisby H. Fracture incidence in adults in relation to age and gender: a study of 27,169 fractures in the Swedish fracture register in a well-defined catchment area. PLoS One. 2020;15(12):e0244291.

27. Axelsson KF, Johansson H, Lundh D, Moller M, Lorentzon M. Association between recurrent fracture risk and implementation of fracture liaison Services in Four Swedish Hospitals: a cohort study. J Bone Miner Res. 2020;35(7):1216-23.

28. Vicenti G, Bizzoca D, Pascarella R, Delprete F, Chiodini F, Daghino W, et al Development of the Italian fractures registry (RIFra): a call for action to improve quality and safety. Injury. 2020. https://doi.org/10.1016/j.injury. 2020.10.052.

29. Bergdahl C, Nilsson F, Wennergren D, Ekholm C, Moller M. Completeness in the Swedish fracture register and the Swedish National Patient Register: an assessment of humeral fracture registrations. Clin Epidemiol. 2021;13:325-33.

30. Wennergren D, Ekholm C, Sundfeldt M, Karlsson J, Bhandari M, Moller M. High reliability in classification of tibia fractures in the Swedish fracture register. Injury. 2016;47(2):478-82.

31. Juto H, Moller M, Wennergren D, Edin K, Apelqvist I, Morberg P. Substantial accuracy of fracture classification in the Swedish fracture register: evaluation of AO/OTA-classification in 152 ankle fractures. Injury. 2016:47(11):2579-83.

32. Wennergren D, Stjernstrom S, Moller M, Sundfeldt M, Ekholm C. Validity of humerus fracture classification in the Swedish fracture register. BMC Musculoskelet Disord. 2017;18(1):251.

33. Morgonskold D, Warkander V, Savvides P, Wihlborg A, Bouzereau M, Moller $\mathrm{H}$, et al. Inter- and intra-rater reliability of vertebral fracture classifications in the Swedish fracture register. World J Orthop. 2019;10(1):14-22.

34. Knutsson SB, Wennergren D, Bojan A, Ekelund J, Moller M. Femoral fracture classification in the Swedish fracture register - a validity study. BMC Musculoskelet Disord. 2019;20(1):197.

35. Bergvall M, Bergdahl C, Ekholm C, Wennergren D. Validity of classification of distal radial fractures in the Swedish fracture register. BMC Musculoskelet Disord. 2021;22(1):587.

36. Kihlstrom C, Moller M, Lonn K, Wolf O. Clavicle fractures: epidemiology, classification and treatment of 2422 fractures in the Swedish fracture register; an observational study. BMC Musculoskelet Disord. 2017;18(1):82.

37. Rydberg EM, Zorko T, Sundfeldt M, Moller M, Wennergren D. Classification and treatment of lateral malleolar fractures - a single-center analysis of 439 ankle fractures using the Swedish fracture register. BMC Musculoskelet Disord. 2020;21(1):521.

38. Rydberg EM, Moller M, Ekelund J, Wolf O, Wennergren D. Does the Covid-19 pandemic affect ankle fracture incidence? Moderate decrease 
in Sweden. Acta Orthop. 2021. https://doi.org/10.1080/17453674.2021. 1907517.

39. Engstrom Z, Wolf O, Hailer YD. Epidemiology of pediatric femur fractures in children: the Swedish fracture register. BMC Musculoskelet Disord. 2020;21(1):796.

40. Bruggemann A, Mukka S, Wolf O. Epidemiology, classification and treatment of olecranon fractures in adults: an observational study on 2462 fractures from the Swedish fracture register. Eur J Trauma Emerg Surg. 2021. https://doi.org/10.1007/s00068-021-01765-2.

41. Bergdahl C, Wennergren D, Ekelund J, Möller M. Mortality after a proximal humeral fracture. Bone Joint J. 2020;102-b(11):1484-90

42. Wolf $\mathrm{O}$, Mukka S, Ekelund J, Moller M, Hailer NP. How deadly is a fracture distal to the hip in the elderly? An observational cohort study of 11,799 femoral fractures in the Swedish fracture register. Acta Orthop. 2020. https://doi.org/10.1080/17453674.2020.1831236

\section{Publisher's Note}

Springer Nature remains neutral with regard to jurisdictional claims in published maps and institutional affiliations.

- fast, convenient online submission

- thorough peer review by experienced researchers in your field

- rapid publication on acceptance

- support for research data, including large and complex data types

- gold Open Access which fosters wider collaboration and increased citations

- maximum visibility for your research: over $100 \mathrm{M}$ website views per year

At BMC, research is always in progress.

Learn more biomedcentral.com/submissions 